\title{
PERCEPTION OF CRIMINALS: WHAT STEREOTYPES HOLD FUTURE LAW ENFORCEMENT OFFICERS?
}

\author{
Laima Ruibyte \\ Evelina Viduoliene \\ Birute Balseviciene \\ Mykolas Romeris University, Faculty of Public Security, Lithuania
}

\begin{abstract}
The main reasons for why stereotypes of police officers about criminals are dangerous and affecting the legal system are: firstly, having stereotypes and misconceptions about typical criminals is damaging witness's ability to correctly identify and/or remember the offender's features; secondly, stereotypes determine the peculiarities of interrogations; thirdly having stereotypes hinders the identification of individuals who actually commit crimes. 270 university students of Law and Police Activity program participated in the study and gave their opinion on the portrait and likely activities of a potential perpetrator. The Criminal Stereotype Questionnaire-Revised (Sparks \& MacLin, 2011) was used to evaluate students' judgment concerning the potential perpetrator's socially desirable/undesirable personality traits, early years of family life history and childhood and adolescence activities. The results of this study revealed that future law and public security officers refer to delinquent activities during childhood and adolescence as well to adverse parental family life circumstances when predicting criminal behavior rather than personality traits. Furthermore, they have some preconceptions about gender, race and criminal behavior in advance.
\end{abstract}

Keywords: criminal stereotypes, law enforcement, students.

\section{Introduction}

Stereotypes are mental representations that individuals have about groups of people (Gilbert \& Hixon, 1991; Macrae et al., 1994; Beilock et al., 2007; Sherman, 2011). These representations usually are what helps people to understand surrounding world and to maximize differences between groups and minimize the differences within the same group (Schneider, 2004; MacLin \& Herrera, 2006; Sekaquaptewa \& Espinoza, 2004). Moreover, usually, group which is stereotyped is considered to be worse and with more negative features than the group to which a person identifies himself (Schaller \& Conway, 2011, Schneider, 2004). Research has shown that people have many stereotypes considering gender, race, ethnicity and other factors that have apparently common features (Schneider, 2004; Beilock et al., 2006). Although stereotypes are inevitable and sometimes useful however they can reduce the possibility to judge about people and their actions objectively. Stereotypes impact all 
information processing and works so that people are looking for their beliefs approvals but not for objective reality (Sekaquaptewa \& Espinoza, 2004; Schneider, 2005; Yarmey, 1993). The consequence of such categorization is perceptual biases: "We" are different individuals, "They" are more homogeneous. These images supported prejudicial feeling, discriminatory behaviour, and even wide scale violence directed against minority-group members or vice versa. While talking about criminal stereotypes it is important to stress that perceptual biases uphold by legal system representatives can negatively affect people's lives and justice (e.g. wrongful convictions (Lewis \& Sommervold, 2015)).

A criminal or perpetrator is a person who perpetrates or commits an illegal or criminal act (MacLin \& Herrera, 2006). Although there are a large amount of literature about stereotypes in general but there is lack of research about criminal stereotypes especially about perceptions of criminals of law enforcement officers or students of this area. Researches in this field show that there are particular stereotypes about appearance, age, race and other similar features of typical potential perpetrator (MacLin \& Herrera, 2006; Allison et al., 2013; Jones \& Kaplan, 2003; Yarmey, 1993). Most studies of this area are conducted in Western countries, which have various race and ethnic minorities. These studies indicate that most likely that typical offender is considered to be Black or Hispanic or immigrants (Madriz, 1997). Researches on perpetrator stereotypes have shown that typical criminal is male, Black (40\%) or Hispanic (30\%) and White (20\%); age average 25 years old (MacLin \& Herrera, 2006). To note studies concerning stereotypes about criminal age are very uncommon (Allison et al., 2013). Moreover, evidence has shown that Black offenders are more likely to be found guilty than White (Jones \& Kaplan, 2003; Najdowsky, 2011; Correll et al., 2007; Welch, 2007). In terms of criminal personality or appearance and social demographic characteristics, most likely that men, who are non - educated, with specific appearance such as tattoos or short hair - cut are found as typical features of perpetrator (MacLin \& Herrera, 2006; Allison et al., 2013; Jones \& Kaplan, 2003; Najdowsky, 2011). Furthermore, stereotypes about sexual abusers and victims most likely are influenced by factors such as perpetrator age, gender, socialization (Denov, 2003; Willis et al., 2013), and ethnic identity (Maxwell et al., 2003). In addition, attitudes about what intervention or penalties should be applied for abusers are connected to the race of respondent (Sahlstrom \& Jeglic, 2009). One study found that if abuser and respondent are different race, than more harsh punishments should be applied for perpetrators (Maxwell et al., 2003); however, this was not supported by the other studies (Sahlstrom \& Jeglic, 2009).

Perception of perpetrators is most likely to be affected by past experience, culture, and the media (Schneider, 2004; Allison et al., 2013). Media is very 
important source for judgment about criminals' features. Specifically, Black criminal stereotype is considered to be associated with how Blacks are portrayed in media (Welch, 2007; Madriz, 1997). Unfortunately, media representations of offenders, especially, child sexual abuses, rarely correspond to reality (Gallagher, 1998). Another factor affecting perceptions of perpetrators is persons own experience or contact with perpetrator. Researchers suggested that absence of contacts with offenders can strengthen stereotypes portrayed in the media (Sahlstrom \& Jeglic, 2009; Kjelsberg \& Loos, 2008). Studies showed that those who have contacts with offenders such as experienced group of professionals uphold less stereotypes about child sexual offenders than the inexperienced professionals or public (Sanghara \& Wilson, 2006; Gakhal \& Brown, 2011).

Although information about objective features of criminals and harmfulness of stereotypes of criminals is more and more available and efforts to overcome stigmatization in recent decades are made, viewing the world as stereotyped reality is very vital. It is important to note, that objective evaluation of reality and people's actions is one of the key features of law enforcement officers (Colwell et al., 2006; Correll et al., 2007; Gakhal \& Brown, 2011). The main reasons for why stereotypes of police officers about criminals are dangerous and affecting the legal system are: firstly, having stereotypes and misconceptions about typical criminals is damaging witness's ability to correctly identify and/or remember the offender's features; secondly, stereotypes determine the peculiarities of interrogations (what questions are given and how witness, offender or victim is interviewed, what tactics is used in the interrogations) (Najdowsky, 2011). Ultimately, having stereotypes hinders the identification of individuals who actually commit crimes. Researches confirm that it is crucial in such crimes as sexual abuse (Harper \& Hogue, 2015; Church et al., 2008; Flowe et al., 2011). That is why it is so important to train the future police officers, so that they have fewer stereotypes of offenders. University students with law enforcement and other criminal justice aspirations embody the future generation primarily responsible for the effects of stereotyping victims and offenders. It is important that these students be assessed and to know if and how education programs could prevent the wrongful stereotypes.

To our knowledge, the current study is the first to use a sample of future law enforcement officers of Lithuania. Comparing to Western countries Lithuania represents very homogenous society concerning the race, ethnicity (Lithuanian Department of Statistics, 2013.), and studies like this provide possibility to examine the stereotypes (on race, ethnicity bases) held by members of such society. Police officers as part of society who confront much more with criminals and have to make fair judgments despite their preconceptions should know and be aware of those stereotypes, so this could 
Laima Ruibyte, Evelina Viduoliene, Birute Balseviciene. Perception of Criminals: what Stereotypes Hold Future Law Enforcement Officers?

prevent law enforcement representatives from wrongful decisions and actions. In this paper we try to find out whether future law enforcement students hold some kind of stereotypical attitudes toward criminals - their personality traits, race, early family life circumstances, childhood and adolescence activities. The study employed psychologically valid instruments to measure the person's opinion concerning different personal and social characteristics of potential perpetrator and complement empirical researches data on criminal stereotypes.

\section{Methodology}

\section{Participants}

270 students of Mykolas Romeris University Public security Faculty from Law and PoliceActivity program participated in the study, $111(41,1 \%)$ of them are male. The age range of the students is 18 to 39 years with mean $M=20,7$ $(\mathrm{SD}=2,7)$ years. $81,5 \%$ of students spent their childhood and adolescence years living with both parents, $8,5 \%$ with single parent, and 10,0\% participants lived with single/divorced parent however had an opportunity to interact and spend time with both of them. $88,1 \%$ of students have siblings, other $11,8 \%$ are the only child in a family.

\section{Measures}

The Criminal Stereotype Questionnaire-Revised (CSQ-R, Sparks \& MacLin, 2011) was used in the study. CSQ-R is a self-report Likert scale type questionnaire which assesses person's opinion concerning potential perpetrator ethnicity, look, activities, personality traits, family status, also probable crime place and circumstances.

Three factors related to potential perpetrator portrait were evaluated. Criminal's personality traits factor consisted of 32 polar traits (e.g. "insecure confident", "mean - kind“, „deceitful-honest, trustworthy“, „passiveaggressive", etc.), with a response scale 1 to 7 . Higher score on this domain represents more socially positive characteristics. Cronbach alpha for this domain is 0,83 .

Early family life circumstances factor consisted of 8 items (e.g. how likely the potential perpetrator was raised by single mother or father, stepparents, group home living as because of orphanage, etc.). The higher score is for this domain, the more positive environment was in early family life. Cronbach alpha for this factor is 0,81 .

Childhood and adolescence activities factor has 14 items that evaluate whether respondents believe that the potential criminal could be involved in activities like bullying, pranks, vandalism, school clubs, etc.). Higher score on this domain represents more positive and socially acceptable activities in childhood or adolescence. Internal consistency for this factor is alpha 0,82 . 
Also, students were asked about their sociodemographic: gender, age, family status in yearly years (lived with both patents, with single parent but was interacting with both of them, single parent), siblings (no/yes), living place in early years ( 1 - city, 4 - countryside), financial strain of parental family during early years of live and personal financial situation during studies (1 - sufficient, 4 - lack).

\section{Procedure}

The questionnaires for participants were anonymous.

SPSS 22.0 package was used for statistical analysis and empirical data. Each domain score range was divided into the categories: up to $20^{\text {th }}$ percentile, 21-79 percentiles and above $80^{\text {th }}$ percentile. Results presented in Table 1 reveal the prevalence for each category.

\section{Results}

According to results (Table 1) participants who study law and public security have no criminal stereotypic attributions concerning potential perpetrator's personality traits in advance (only one student reported that the potential criminal may be characterized by exceptionally undesirable character elements and none of the participants thought this person may be described by particularly socially positive characteristics). However, most of the students have attributions related to potential perpetrator's early family life circumstances and early life social activities. 19,3\% of the participants considered the potential perpetrator having inauspicious early family life circumstances (single parent, adoption, custody history). 36,3\% of the participants believed that potential perpetrator has a history of delinquent activities in early years.

Table 1 Prevalence of potential perpetrator's characteristics range groups

\begin{tabular}{|c|c|c|c|}
\hline \multirow[b]{2}{*}{$\begin{array}{c}\text { Domains/ } \\
\text { characteristics }\end{array}$} & \multicolumn{3}{|c|}{ Characteristics range $(\mathrm{N}, \%)$} \\
\hline & $\begin{array}{l}\text { Up to } 20^{\text {th }} \text { percentile } \\
\text { (exceptionally } \\
\text { undesirable elements, } \\
\text { circumstances) }\end{array}$ & $\begin{array}{c}\text { 21-79 percentile } \\
\text { (no stereotypic } \\
\text { criminal } \\
\text { attribution) }\end{array}$ & $\begin{array}{c}\text { Above } 80^{\text {th }} \text { percentile } \\
\text { (exceptionally } \\
\text { positive elements, } \\
\text { circumstances) }\end{array}$ \\
\hline $\begin{array}{c}\text { Criminal's } \\
\text { personality traits }\end{array}$ & $1(0,4 \%)$ & $269(99,6 \%)$ & 0 \\
\hline $\begin{array}{l}\text { Early family life } \\
\text { circumstances }\end{array}$ & $52(19,3 \%)$ & $216(80,0 \%)$ & $2(0,7 \%)$ \\
\hline $\begin{array}{l}\text { Childhood and } \\
\text { adolescence } \\
\text { activities }\end{array}$ & $98(36,3 \%)$ & $171(63,3 \%)$ & $1(0,4 \%)$ \\
\hline
\end{tabular}


The second question of the study was to evaluate which students' demographic characteristics may predict such negative exceptionally socially undesirable early life activities and living circumstances of potential criminal. Two logistic regressions were performed and dependent variable was 2 groups of students who have no stereotypic criminal attributions and who have particularly socially undesirable attributions related to potential criminal's social activities or family life circumstances. Participant's gender, age, family status in yearly years, siblings, living place in early years, financial strain of parental family during early years of live and personal financial situation during studies were included in regression model as independent variables.

Results revealed that none of independent variables predict attributions related to potential perpetrator's early family life circumstances $\left(\chi^{2}=8,623\right.$, $\mathrm{df}=14, \mathrm{p}=0,854$; all odds ratios $(\operatorname{Exp}(B))$ are statistically insignificant $)$.

According to results there is statistical tendency that regression model that predicts predict negative stereotypic attributions related to potential perpetrator's early life activities may be appropriate $-\chi^{2}=21,372, \mathrm{df}=14, \mathrm{p}=0,092$. The only independent variable may predict exceptionally undesirable social attributions growing up without siblings $(\operatorname{Exp}(B)=0,338, p=0,009$, other odds ratios are statistically insignificant). Being a single child in a family predicts that participant's position.

The third question of the study was to evaluate which elements of potential criminal appearance, looking, social activities, family life circumstances, and personality traits gained extreme points - these elements may be assumed being an attributions or stereotypes. As each element could be rated 1 to 7 , we have excluded elements that both mode and median were less than 3 or greater than 5 .

Results revealed that students assume that potential criminal may wear dark and baggy clothes, color of his hair is dark, having tattoos on body, and very unlikely having body piercings. According to students is it very unlikely that potential criminal participated in scouts, religious activities, student government or school clubs, by contrast it is very likely that potential perpetrator participated in teasing others, bullying, animal torture, stealing, pranks and vandalism acts, was living in foster home. Most participants agreed that it is very likely that this person is aggressive, deceitful, mean and irritable, has alcohol and substance abuse problems. 77,4 percent of students believe that probability that potential criminal is male is greater than 0,7 .

Considering the perpetrator's race, most participants stated that white and Roma people were more likely to perform a crime compared to Asian and black people. 


\section{Discussion}

Analyses of results show that future law enforcement students do not hold strong preconceptions concerning potential perpetrator's appearance although some components of stereotype could be mentioned. Some elements of potential criminal appearance (e.g. wearing dark and baggy clothes, dark color hair, having tattoos on body, and very unlikely having body piercing) were associated with perpetrator. In MacLin \& Herrera study there are considerably more features attributed to criminal - wearing baggy, dirty and/or black clothing, being tall with long or shaggy dark hair; the stereotypical criminal have some form of facial hair, and beady eyes, tattoos, scars and pock marks, accessories like gloves, hats, and bandanas (MacLin \& Herrera, 2006).

The believe of participant that potential criminal is male correspondent with findings in another similar studies (MacLin \& Herrera, 2006; Allison et al., 2013) and this notion reflect real situation of male in the offender population (http://law.jrank.org/pages/1250/Gender-Crime-Differences-between-malefemale-offending-patterns.html).

The most students stated that Roma people were more likely to perform a crime than other ethnicities and this may reflect stereotypical view formed by massive media information about criminal acts (usually drug sales) happen in Roma residence (tabor). 2,000 Roma people constitute only 0,1 percent of total population in Lithuania therefore such notion are highly stereotypical.

Future law enforcement students have strong believe that being criminal associated with exceptionally negative socially disadvantageous early life activities and living circumstances, like single parent, adoption, custody history, history of delinquent activities in early years. Most participants agreed that it is very likely that this person is aggressive, deceitful, mean and irritable, has alcohol and substance abuse problems, participated in teasing others, bullying, animal torture, stealing, pranks and vandalism acts, was living in foster home. It can be viewed as quite harsh schema of potential criminal even though it corresponds to a large extent the characteristics of the real criminals but not every.

Some differences from results of previous studies (MacLin \& Herrera, 2006; Allison et al., 2013; Jones \& Kaplan, 2003) could be explained by fact that participants in our study was more educated in the field of criminal justice and criminology. As results revealed none of independent variables predicted attributions related to potential perpetrator's yearly family life circumstances and childhood and adolescence activities so we could hypothesized that knowledge about criminals gained in lectures could form such preconceptions toward criminals. The question what factor (e.g. media, education, experience and direct confrontation) and how it could shape the schemas of potential 
Laima Ruibyte, Evelina Viduoliene, Birute Balseviciene. Perception of Criminals: what Stereotypes Hold Future Law Enforcement Officers?

perpetrator should be explored in future researches. Aware of criminal stereotypes and understanding how they are formed has important implications for the education of law enforcement professionals and the criminal justice system in general.

\section{Conclusions}

Students of law and public security have no criminal stereotypic attributions concerning potential perpetrator's personality traits in advance, however they considered the potential perpetrator having inauspicious early family life circumstances and a history of delinquent activities in early years. Most of the participants believed that perpetrators are normally male, also white and Roma people were more likely to perform a crime compared to Asian and black people. Some elements of potential criminal appearance, looking, social activities, family life circumstances, personality traits were excluded that may be attributed to criminals.

\section{References}

Akehurst, L., Köhnken, G., Vrij, A., \& Bull, R. (1996). Lay persons' and police officers' beliefs regarding deceptive behavior. Applied Cognitive Psychology, 10, 461-471.

Allison, M., Sweeney, L., \& Jung, S. (2013). A Comparison of Canadian and American Offender Stereotypes. North American Journal of Psychology, 15 (3), 589-607.

Beilock, S. L., Jellison, W. A., Rydell, R. J., McConnell, A. R., \& Carr, T. H. (2006). On the causal mechanisms of stereotype threat: Can skills that don't rely heavily on working memory still be threatened? Personality and Social Psychology Bulletin, 32, 10591071.

Beilock, S. L., Rydell, R. J., \& McConnell, A. R. (2007). Stereotype threat and working memory: Mechanisms, alleviation, and spillover. Journal of Experimental Psychology: General, 136, 256-276.

Church, W. T., Wakeman, E. E., Miller, S. L., Clements, C. B., \& Sun, F. (2008). The community attitudes toward sex offenders scale: The development of a psychometric assessment instrument. Research on Social Work Practice, 18, 251-259.

Colwell, L. H., Miller, H. A., Lyons, P. M., Jr., \& Miller, R. S. (2006). The training of law enforcement officers in detecting deception: A survey of current practices and suggestions for improving accuracy. Police Quarterly, 9, 275-290.

Correll, J., Park, B., Judd, C. M., Wittenbrink, B., Sadler, M. S., \& Keesee, T. (2007). Across the thin blue line: Police officers and racial bias in the decision to shoot. Journal of Personality and Social Psychology, 92, 1006-1023.

Flowe, H. D., \& Humphries, J. E. (2011). An examination of criminal face bias in a random sample of police lineups. Applied Cognitive Psychology, 25 (2), 265-273.

Gilbert, D. T., \& Hixon, J. G. (1991). The Trouble of Thinking Activation and Application of Stereotypic Beliefs. Journal of Personality and Social Psychology, by the American Psychological Association, 60 (4), 509-517 
Harper, C. A., \& Hogue, T. E. (2015). Measuring public perceptions of sex offenders: reimagining the Community Attitudes Toward Sex Offenders (CATSO) scale. Psychology, Crime \& Law, 21 (5), 452-470.

Jones, C. S., \& Kaplan, M. F. (2003). The effects of racially stereotypical crimes on juror decision-making and information-processing strategies. Basic and Applied Social Psychology, 25 (1), 1-13.

Lewis, A. L., \& Sommervold, S. L. (2015). Death, but is it murder? The role of stereotypes and cultural perceptions in the wrongful convictions of women. Albany Law Review, 78 (3), 1035-1058.

Republic of Lithuania, the 2011 Population and Housing Census Results. (2013). Lithuanian Department of Statistics [Data file]. Retrieved from https://osp.stat.gov.lt/documents/ 10180/217110/Gyv_kalba_tikyba.pdf/1d9dac9a-3d45-4798-93f5-941fed00503f.

MacLin, M. K., \& Herrera, V. (2006). The criminal stereotype. North American Journal of Psychology, 8 (2), 197-208.

MacLin, O. H., \& MacLin, M. K. (2004). The effect of criminality on face attractiveness, typicality, memorability, and recognition. North American Journal of Psychology, 6, $145-154$.

Macrae, N. C., Milne, A. B., \& Bodenhausen, G. V. (1994). Stereotypes as energy-saving devices: A peek inside the cognitive toolbox. Journal of Personality and Social Psychology, 66 (1), 37-47

Madriz, E. I. (1997). Images of criminals and victims: A study on women's fear and social control. Gender and Society, 11, 342-256.

Najdowski, C. J. (2011). Stereotype threat in criminal interrogations: Why innocent Black suspects are at risk for confessing falsely. Psychology, Public Policy, and Law, 17 (4), $562-591$.

Sanghara, K., \& Wilson, C. (2006). Stereotypes and attitudes about child sexual abusers: A comparison of experienced and inexperienced professionals in sex offender treatment. Legal and Criminological Psychology, 11, 229-244.

Schaller, M., \& Conway, L. G. (2011). From cognition to culture: the origins of stereotypes that really matters. In: Moskowitz, G. B. (Ed.) Cognitive Social Psychology: the Princeton Symposium on Legacy and Future of Social Cognition. (p.p. 177-190). Taylor $\&$ Fransis e-Library.

Schneider, D. J. (2005). The psychology of stereotyping. NY: Guilford Press.

Sekaquaptewa, D., \& Espinoza, P. (2004). Biased processing of stereotype - incongruence is greater for low than high status groups. Journal of Experimental Social Psychology, 40, $128-135$.

Sherman, J. W. (2011). The dynamic relationship between stereotype efficiency and mental representation. In: Moskowitz G. B. (Ed.) Cognitive Social Psychology: the Princeton Symposium on Legacy and Future of Social Cognition. (p.p. 163-176). Taylor \& Fransis e-Library.

Sparks, A. M., \& MacLin, M. (2011). „Criminal Stereotypes Questionnaire-Revised”. Paper presented at the annual meeting of the American Psychology - Law Society (2011-0302). 4th International Congress of Psychology and Law, Hyatt Regency Miami, Miami, FL.

Welch, K. (2007). Black criminal stereotypes and racial profiling. Journal of Contemporary Criminal Justice, 23, 276-288.

Yarmey, D. A. (1993), Stereotypes and recognition memory for faces and voiced of good guys and bad guys. Applied Cognitive Psychology, 7, 419-431. 